
About IJMA [last updated July, $\left.1^{\text {st }}, 2021\right]$

$\checkmark$ International Journal of Medical Arts is the Official Journal of the Damietta Faculty of Medicine, AlAzhar University, Egypt

$\checkmark$ It is an International, Open Access, Double-blind, Peer-reviewed Journal

$\checkmark$ Published four times a year

$\checkmark$ The First Issue was published in July 2019

$\checkmark$ Published under the following license: Creative Commons Attribution-ShareAlike 4.0 International Public License (CC BY-SA 4.0). It had updated from the Creative Commons license [CC BY] in volume 2, Issue 4, October 2020 About IJMA

$\checkmark$ The Egyptian Knowledge Bank hosts the web site of IJMA

$\checkmark$ The Egyptian Knowledge Bank supports IJMA

$\checkmark$ IJMA follows the regulations of the International Committee of Medical Journal Editors

$\checkmark$ IJMA is indexed in the "Directory of Open Access Journals" [15 January 2021].

$\checkmark$ IJMA is indexed in JGate [29-6-2021]

$\checkmark$ IJMA is a member of the International Society of Managing and Technical Editors

$\checkmark$ Listed in "Index Copernicus", "Publons", "Academic resource index [ResearchBib]", "Electronics journal library", "Eurasian Scientific Journal Index", and "Citefactor"

$\checkmark$ IJMA introduced to the search engine [BASE] through DOAJ
Click image to reach the page

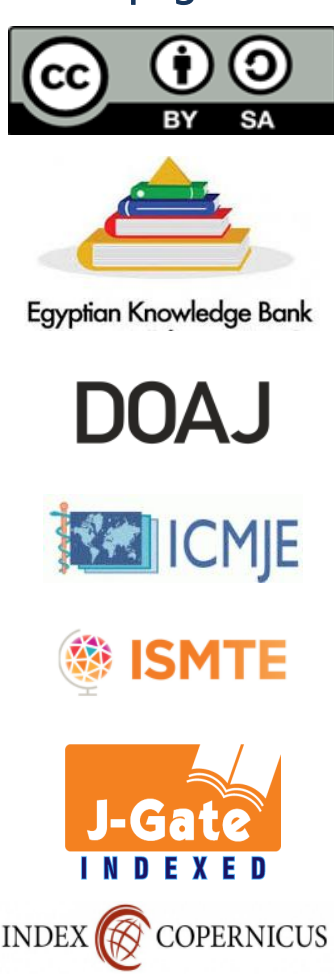

publons

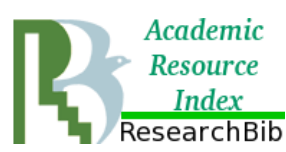

\section{EZ3 \\ .}

ESJII

CiteFactor

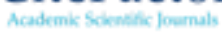

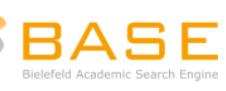




Available online at Journal Website
https://ijma.journals.ekb.eg/
Main subject [Obstetrics; Anesthesiology]

Original Article

\title{
Ketamine versus Dexmedetomidine in Local Wound Infiltration for Postoperative Pain Relief in Cesarean Section
}

\author{
Nourhan R. Biomy [1], Asmaa Fathelbab [2], Amina Abdel-Fattah [2], Abeer E. Farhat ${ }^{[3]}$ \\ ${ }^{1}$ Department of Obstetrics and Gynecology, El Hawamdyia General Hospital, Ministry of Health, Egypt. \\ 2 Department of Obstetrics and Gynecology, Faculty of Medicine, Al-Azhar University, Egypt. \\ ${ }^{3}$ Department of Anesthesia and Intensive Care, Faculty of Medicine for Girls, Al-Azhar University, Egypt. \\ Corresponding author: Amina Abdel-Fattah \\ amona_update@yahoo.com
}

Received: June 20, 2021; Accepted: July 17, 2021.

DOI: 10.21608/ijma.2021.185126

DOAJ

\section{ABSTRACT}

Background: Cesarean delivery is a frequently obstetric operation in Egypt with a recently reported over all cesarean section rate of $54 \%$ and it causes moderate to severe postoperative discomfort. Infiltration of the wound site is a method to improve postoperative analgesia.

The aim of the work: To compare the pain relief effects of ketamine versus dexmedetomidine combined to bupivacaine in local wound infiltration in patients undergoing cesarean section and to estimate side effects of medications.

Patients and Methods: This randomized, controlled study including 90 women were subjected for elective cesarean delivery under general anesthesia and were divided at random into 3 equal groups to receive $40 \mathrm{ml}$ bupivacaine [0.25\%] + either $2 \mathrm{mg} / \mathrm{kg}$ ketamine in [group A], $2 \mu \mathrm{g} / \mathrm{kg}$ dexmedetomidine in [group B] or $2 \mathrm{ml}$ saline in [group C] via local wound infiltration. The primary outcome was the time of the first analgesia requested. The secondary outcomes were total dose of analgesia per 24 hours, visual analogue scale, the time of starting movement, breast-feeding, passing flatus or stool, start of eating and adverse effects of medications.

Results: A significant increase in time of the first analgesic request in group $A$ [8.4 \pm 1.91$] \mathrm{h}$. and group $B$ [7.5 \pm 1.81$] \mathrm{h}$. than group $C$ [4.3 \pm 1.24$] \mathrm{h}$. A significant decrease in pethidine consumption in group $A[59 \pm 28.93 \mathrm{mg}]$ than group $B$ [72 $\pm 23.1 \mathrm{mg}]$ and group C [102 $\pm 16 \mathrm{mg}$ ]. The visual analogue scale [VAS] was significantly lower $[p<0.001]$ in groups $A$ and $B$ than in group $C$. The time of start movement, breast-feeding, passing flatus and eating was decreased in groups $A$ and $B$ than in group $C$

Conclusions: Addition of ketamine or dexmedetomidine to local anesthetics wound infiltration increased time to the first analgesia request and decreased total analgesic consumption, but ketamine is superior.

Keywords: Ketamine; Dexmedetomidine; Local anesthesia; Wound Infiltration.

This is an open-access article registered under the Creative Commons, ShareAlike 4.0 International license [CC BY-SA 4.0] [https://creativecommons.org/licenses/by-sa/4.0/legalcode.

Citation: Biomy NR, Fathelbab A, Abdel-Fattah A, Farhat AE. Ketamine versus Dexmedetomidine in Local Wound Infiltration for Postoperative Pain Relief in Cesarean Section. IJMA 2021; 3 [3] July-September: 1570-1575. [DOI: 10.21608/ijma.2021.185126].

Main subject and any subcategories have been classified according to the research topic.




\section{INTRODUCTION}

post-cesarean pain is unpleasant sensation that occurs as a result of tissue damage, and indicates that the body has been injured ${ }^{[1]}$.

Post-operative pain management is essential since women are expected to recover rapidly and care for their newborns within a few hours following surgery ${ }^{[2]}$. As a result, utilizing a safe, uncomplicated, and effective analgesic is recommended ${ }^{[3]}$.

Effective postoperative analgesia can enhance recovery and decrease morbidity [4]. Local anesthetics wound infiltration is an adequate technique for pain management after many operations and can decrease postoperative analgesic requirements ${ }^{[5]}$.

It is an easy, effective and costless technique can enhance postoperative analgesia for different types of operations without major complications ${ }^{[6]}$.

In terms of somatic pain control, a variety of systemic and local anesthetic approaches have been employed to treat Post-cesarean pain [7].

Ketamine is a central and peripheral analgesic that works by blocking the N-methyl-D-aspartate [NMDA] receptor ${ }^{[8]}$.

Dexmedetomidine is a highly selective agonist of a 2 adrenergic receptor with sedative, analgesic but not anesthetic characters. So, it's safe as an adjuvant in various clinical applications ${ }^{[8]}$.

\section{AIM OF THE WORK}

In the current work, we aimed to compare the pain relief effects of ketamine versus dexmedetomidine combined to bupivacaine in local wound infiltration in patients underwent cesarean section and to estimate side effects of medications.

\section{PATIENTS AND METHODS}

Following the approval of the local ethics committee and the signed informed consent of each parturient, this randomized double-blind controlled study was conducted on 90 women American Society of Anesthesiologists [ASA] I and II. They were subjected to elective cesarean delivery under general anesthesia in Al-zahraa University Hospital from January 2019 to January 2020.
Inclusion criteria for pregnant women were, primigravida with singleton fetus, age between 20 and 40 years, weight between 60 and $85 \mathrm{~kg}$ and height between 155 and $170 \mathrm{~cm}$, patients with no obstetric complication [pre-eclampsia and antepartum hemorrhage].

Exclusion criteria were patient refusal, multiple pregnancy, the procedure lasted more than one hour, drug abuse, history of allergy to the study drugs, diabetes mellitus, heart, liver, kidney, coagulation or mental disorders and local infection of previous cesarean scar.

Pre-operative assessment was done for each parturient before cesarean section by history [personal, medical, surgical, obstetric], examination [general, local and airway] and routine investigations. Each parturient was trained on the use of visual analogue scale [VAS] by an anesthesialogist who was not involved in the study. Visual analogue scale, which was used for pain assessment is a horizontal line, $10 \mathrm{~cm}$ in length ranging from $0=$ [no pain] to $10=$ [worst pain].

A computer-generated random number was used to allocate the patients into one of the three groups: Group $A$ [n=30]: given $40 \mathrm{~mL}$ of bupivacaine [0.25\%] $+2 \mathrm{mg} / \mathrm{kg}$ ketamine by local wound infiltration. Group $B$ [n=30]: given $40 \mathrm{~mL}$ bupivacaine [0.25\%] $+2 \mu \mathrm{g} / \mathrm{kg}$ dexmedetomidine by local wound infiltration. Group C [n=30]: given $40 \mathrm{~mL}$ bupivacaine $[0.25 \%]+2 \mathrm{ml}$ saline by local wound infiltration.

Drugs used in wound infiltration were prepared by anesthesia residents who had no rule in the study.

In the operating room, intravenous cannula was inserted and ringer acetate solution $[10 \mathrm{ml} / \mathrm{kg} / \mathrm{h}$ ] was started, patients were attached to the standard monitor [Fabius Gs, Germany] as electrocardiography, pulse oximetry and non-invasive blood pressure. Prior to the induction of anesthesia, the mother's heart rate $[\mathrm{HR}]$ and mean arterial pressure [MAP] were monitored.

After preoxygenation [for five minutes], women received general anesthesia by intravenous propofol [1.5 $\mathrm{mg} / \mathrm{kg}]$, atracurium $[0.5 \mathrm{mg} / \mathrm{kg}]$. The maintenance of anesthesia was achieved by oxygen/ air mixture, sevoflurane [2\%], atracurium [0.1 $\mathrm{mg} / \mathrm{kg}]$ if required and fentanyl $50 \mu \mathrm{g}$, after delivery of the fetus, HR and MAP were recorded each 10 minutes interval through the surgery.

Before wound closure, women received intra-incisional infiltration of $40 \mathrm{ml}$ bupivacaine [0.25\%] plus either $2 \mathrm{mg} / \mathrm{kg}$ ketamine in [group A], $2 \mu \mathrm{g} / \mathrm{kg}$ dexmedetomidine in [group 
B] or $2 \mathrm{ml}$ saline in [group C] through infiltration in the anterior and posterior layer of the rectus sheath [transversalis fascia and parietal peritoneum], subcutaneous tissue and skin on upper and lower edges of surgical wound. At the end, neostigmine [0.04-0.06 mg/kg] and atropine $[0.01 \mathrm{mg} / \mathrm{kg}]$ were used to counteract neuromuscular blockade. Women were sent to the postanesthesia care unit [PACU] for a continued surveillance after extubation. HR and MAP were measured every 30 minutes post-operative until the patient was discharged from [PACU]. VAS was used to assess pain at $1,2,3,4,6,8,12,18$, and $24 \mathrm{~h}$ postoperatively. Visual analogue scale $\geq 4$ was treated with meperidine $0.5 \mathrm{mg} / \mathrm{kg}$ intravenous.

The time of the first analgesic request, total dose of analgesic consumption per 24 hours, time to start movement, breast-feeding, eating and passing flatus or stool and side effects of medications were recorded [nausea, vomiting, bradycardia and hypotension]. Hear rate $<60 \mathrm{~b} /$ min was managed by intravenous atropine [0.5 $\mathrm{mg}$. MAP drops $>20 \%$ of baseline value was managed by intravenous fluid and intravenous ephedrine 6-12 mg. Ondansetron $4 \mathrm{mg}$ was used to treat nausea and vomiting.

\section{Statistical analysis}

The data was collected and analyzed by IBM SPSS v23 [Armonk, NY, USA]. The mean, standard deviation [SD] and median Interquartile range [IQR]" were used to express quantitative data. Qualitative information presented as a number or \%. The One-Way ANOVA test was used to compare more than two groups using quantitative data and parametric distribution, with post hoc analysis by least significant differences [LSD]. While Kruskall Wallis test was used for data with a nonparametric distribution. Confidence interval $95 \%$ and error margin $5 \%$. Statistical significance if $P$ value less than 0.05 .

\section{RESULTS}

In this study, 126 women were assessed for eligibility, 29 women did not meet the criteria and 7 women refused to participate in the study. The remaining 90 women were randomly assigned to three equal groups. The demographic data and the duration of surgery were comparable between groups being studied [P-value $>0.05]$, as shown in table 1.

Table [2] reveals significant increase in the time of the first analgesic request in group $A$ [8.4 $\pm 1.91 \mathrm{~h}]$ and group $B[7.5 \pm 1.81 \mathrm{~h}]$ than group $C[4.3 \pm 1.24 \mathrm{~h}]$. A significant decrease in pethidine consumption in group $A[59.0 \pm$ $28.93 \mathrm{mg}]$ than group $B[72.0 \pm 23.1 \mathrm{mg}]$ and group $C$ [102.0 $\pm 16.9 \mathrm{mg}]$.

The visual analogue scale was significantly reduced in group $A$ and $B$ than in group $C$, but group $A$ was superior [Table 3].

Table [4] is showing a reduction in the time of start breast-feeding, passing flatus or stool, start of eating and movement in group $A$ and group $B$ than in group $C$.

Table [5] demonstrates that group $B$ had much more bradycardia than group $A$ and group $C[P=0.003]$, whereas no significant difference was detected for nausea and vomiting or hypotension.

Table [1]: The demographics of the study groups.

\begin{tabular}{|c|c|c|c|c|c|c|c|}
\hline \multirow{2}{*}{\multicolumn{2}{|c|}{ Variable }} & Group $[A]$ & Group [B] & Group [C] & \multirow{3}{*}{$\begin{array}{l}\begin{array}{l}\text { Test } \\
\text { value }\end{array} \\
0.347\end{array}$} & \multirow[t]{2}{*}{ P-value } & \multirow[t]{2}{*}{ Sig } \\
\hline & & No. $=30$ & No. $=30$ & No. $=30$ & & & \\
\hline \multirow{2}{*}{ Age [years] } & Mean $\pm S D$ & $29.40 \pm 5.37$ & $30.47 \pm 5.89$ & $30.43 \pm 5.63$ & & \multirow[t]{2}{*}{0.708} & \multirow[t]{2}{*}{ NS } \\
\hline & Range & $21-40$ & $20-39$ & $21-40$ & & & \\
\hline \multirow[t]{2}{*}{ Weight [kg] } & Mean $\pm S D$ & $72.13 \pm 8.31$ & $69.63 \pm 7.19$ & $73.87 \pm 8.27$ & \multirow[t]{2}{*}{2.156} & \multirow[t]{2}{*}{0.122} & \multirow[t]{2}{*}{ NS } \\
\hline & Range & $60-85$ & $60-83$ & $61-85$ & & & \\
\hline \multirow[t]{2}{*}{ Height [cm] } & Mean $\pm S D$ & $163.80 \pm 4.10$ & $163.27 \pm 4.73$ & $161.90 \pm 4.54$ & \multirow[t]{2}{*}{1.446} & \multirow[t]{2}{*}{0.241} & \multirow[t]{2}{*}{ NS } \\
\hline & Range & $157-170$ & $156-170$ & $155-169$ & & & \\
\hline \multirow{2}{*}{$\begin{array}{l}\text { The duration of } \\
\text { surgery [min] }\end{array}$} & Mean $\pm S D$ & $44.67 \pm 9.76$ & $46.70 \pm 10.08$ & $47.17 \pm 8.89$ & \multirow[t]{2}{*}{0.577} & \multirow[t]{2}{*}{0.564} & \multirow[t]{2}{*}{ NS } \\
\hline & Range & $30-60$ & $31-60$ & $31-60$ & & & \\
\hline
\end{tabular}

P-value $<0.05$ : Significant [S] $\bullet:$ One-Way ANOVA test. The information is displayed as [Mean $\pm \mathrm{SD}]$ and range.

Table [2]: Comparison of the three groups in terms of the first analgesic requirement and total pethidine consumption.

\begin{tabular}{|c|c|c|c|c|c|c|c|}
\hline \multicolumn{2}{|l|}{ Variable } & Group $[A]$ & Group [B] & Group [C] & \multicolumn{3}{|l|}{$P$ value } \\
\hline \multirow{3}{*}{$\begin{array}{l}\text { The first analgesic } \\
\text { requirement [h] }\end{array}$} & Mean \pm SD & $8.4 \pm 1.91$ & $7.5 \pm 1.81$ & $4.3 \pm 1.24$ & \multirow[t]{3}{*}{$<0.001^{*}$} & $\mathrm{P} 1$ & 0.034 \\
\hline & \multirow[t]{2}{*}{ Range } & \multirow[t]{2}{*}{$6-12$} & \multirow[t]{2}{*}{$5-10$} & \multirow[t]{2}{*}{$3-6$} & & P2 & $<0.001$ \\
\hline & & & & & & P3 & $<0.001$ \\
\hline \multirow{3}{*}{$\begin{array}{l}\text { Total pethidine } \\
\text { consumption [mg] }\end{array}$} & Mean \pm SD & $59 \pm 28.93$ & $72 \pm 23.1$ & $102 \pm 16.9$ & \multirow[t]{3}{*}{$<0.001^{*}$} & P1 & 0.035 \\
\hline & \multirow[t]{2}{*}{ Range } & \multirow[t]{2}{*}{$30-120$} & \multirow[t]{2}{*}{$30-120$} & \multirow[t]{2}{*}{$60-120$} & & $\mathrm{P} 2$ & $<0.001$ \\
\hline & & & & & & P3 & $<0.001$ \\
\hline
\end{tabular}

P1: P value between group A and group B, P2: P value between group A and group C, P3: P value between group B and group C.P-value $<0.05$ : Significant. 
Table [3]: Comparison among the three groups with respect to VAS

\begin{tabular}{|l|l|c|c|c|c|c|c|c|c|}
\hline \multicolumn{2}{|l|}{ VAS } & Group [A] & Group [B] & Group [C] & $\begin{array}{c}\text { Test } \\
\text { value }\end{array}$ & P-value & P1 & P2 & P3 \\
\cline { 3 - 7 } & & & & 1.813 & 0.043 & 0.315 & 0.021 & 0.037 \\
\hline $1 \mathrm{hr}$ & Median [IQR] & $0[0-1]$ & $0.5[0-1]$ & $1[0-3]$ & 13 & & & \\
\hline $2 \mathrm{hr}$ & Median [IQR] & $0[0-1]$ & $0.5[0-2]$ & $2[1-3]$ & 2.215 & 0.033 & 0.214 & 0.042 & 0.038 \\
\hline $3 \mathrm{hr}$ & Median [IQR] & $1[0-2]$ & $1[0-3]$ & $3[2-4]$ & 2.452 & 0.021 & 0.715 & 0.007 & 0.032 \\
\hline $4 \mathrm{hr}$ & Median [IQR] & $1[0-2]$ & $2[1-3]$ & $3[2-5]$ & 4.315 & 0.007 & 0.072 & 0.011 & 0.027 \\
\hline $6 \mathrm{hr}$ & Median [IQR] & $2[1-3]$ & $3[2-4]$ & $4[3-6]$ & 5.215 & 0.001 & 0.213 & 0.001 & 0.021 \\
\hline $8 \mathrm{hr}$ & Median [IQR] & $2[1-3]$ & $3.5[3-5]$ & $5[4-7]$ & $4 . .325$ & 0.027 & 0.412 & 0.009 & 0.017 \\
\hline $12 \mathrm{~h}$ & Median [IQR] & $4[3-6]$ & $5[4-7]$ & $6[5-7]$ & 2.314 & 0.031 & 0.089 & 0.037 & 0.092 \\
\hline $18 \mathrm{~h}$ & Median [IQR] & $3[1-3]$ & $3[2-4]$ & $3[2-4]$ & 1.123 & 0.321 & 0.514 & 0.413 & 0.364 \\
\hline $24 \mathrm{~h}$ & Median [IQR] & $3[2-5]$ & $3[2-5]$ & $3[2-5]$ & 0.762 & 0.613 & 0.614 & 0.346 & 0.369 \\
\hline
\end{tabular}

P-value <0.05: Significant [S]. P1: Comparison between group A and group B, P2: Comparison between group A and group C and P3: Comparison between group B and group C.

Table [4]: Comparison between the three groups regarding the time of start breast-feeding, passing flatus or stool and start of eating and movement.

\begin{tabular}{|c|c|c|c|c|c|c|c|}
\hline \multirow{2}{*}{\multicolumn{2}{|c|}{ Variable }} & \multirow{2}{*}{$\begin{array}{l}\text { Group }[\mathrm{A}] \\
\text { No. }=30\end{array}$} & Group [B] & Group[C] & \multirow{2}{*}{$\begin{array}{l}\text { Test } \\
\text { value }\end{array}$} & \multirow[t]{2}{*}{ P-value } & \multirow[t]{2}{*}{ Sig. } \\
\hline & & & No. $=30$ & No. $=30$ & & & \\
\hline \multirow[t]{2}{*}{ Time of start breast-feeding [h.] } & Mean \pm SD & $3.33 \pm 1.21$ & $3.67 \pm 1.03$ & $4.57 \pm 1.19$ & \multirow[t]{2}{*}{9.262} & \multirow[t]{2}{*}{0.000} & \multirow[t]{2}{*}{$\mathrm{HS}$} \\
\hline & Range & $2-5$ & $2-5$ & $3-6$ & & & \\
\hline \multirow{2}{*}{$\begin{array}{l}\text { Time of passing flatus or stool } \\
\text { and start of eating [h.] }\end{array}$} & Mean $\pm S D$ & $4.63 \pm 1.75$ & $5.23 \pm 2.14$ & $6.23 \pm 1.79$ & \multirow[t]{2}{*}{5.401} & \multirow[t]{2}{*}{0.006} & \multirow[t]{2}{*}{ HS } \\
\hline & Range & $2-7$ & $2-8$ & $3-9$ & & & \\
\hline \multirow[t]{2}{*}{ Time of start movement [h.] } & Mean $\pm S D$ & \multirow{2}{*}{$\frac{3.53 \pm 1.17}{2-5}$} & $3.83 \pm 0.99$ & $4.63 \pm 1.16$ & \multirow[t]{2}{*}{7.917} & \multirow[t]{2}{*}{0.001} & \multirow[t]{2}{*}{ HS } \\
\hline & Range & & $2-5$ & $3-6$ & & & \\
\hline \multicolumn{8}{|l|}{ Post hoc Analysis by LSD test } \\
\hline \multicolumn{2}{|l|}{ Parameters } & & $\mathrm{P} 1$ & \multicolumn{2}{|c|}{ P2 } & \multicolumn{2}{|c|}{ P3 } \\
\hline \multicolumn{2}{|l|}{ Time of starting breast-feeding [h.] } & & 0.264 & \multicolumn{2}{|c|}{0.003} & \multicolumn{2}{|c|}{0.000} \\
\hline \multicolumn{2}{|c|}{ Time of passing flatus or stool and start of eating [h.] } & & 0.226 & \multicolumn{2}{|c|}{0.045} & \multicolumn{2}{|c|}{0.002} \\
\hline \multicolumn{2}{|c|}{ Time of start movement [h.] } & & 0.297 & \multicolumn{2}{|c|}{0.006} & \multicolumn{2}{|c|}{0.000} \\
\hline
\end{tabular}

P-value <0.05: Significant [S]., P1: P value between group A and group B, P2: P value between group A and group C and P3: P value between group B and group C.

Table [5]: Adverse effects of medications in the study group.

\begin{tabular}{|c|c|c|c|c|c|c|c|c|c|}
\hline \multirow[t]{2}{*}{ Variable } & \multicolumn{2}{|c|}{ Group $[A]$} & \multicolumn{2}{|c|}{ Group [B] } & \multicolumn{2}{|c|}{ Group [C] } & \multirow[t]{2}{*}{ Test value* } & \multirow[t]{2}{*}{ P-value } & \multirow[t]{2}{*}{ Sig. } \\
\hline & No. & $\%$ & No. & $\%$ & No. & $\%$ & & & \\
\hline Nausea & 3 & $10.0 \%$ & 3 & $10.0 \%$ & 4 & $13.3 \%$ & 0.225 & 0.894 & NS \\
\hline Vomiting & 1 & $3.3 \%$ & 1 & $3.3 \%$ & 2 & $6.7 \%$ & 0.523 & 0.770 & NS \\
\hline Bradycardia & 0 & $0.0 \%$ & 7 & $23.3 \%$ & 1 & $3.3 \%$ & 11.799 & $0.003^{*}$ & $\mathrm{HS}$ \\
\hline Hypotension & 0 & $0.0 \%$ & 2 & $6.7 \%$ & 2 & $6.7 \%$ & 2.093 & 0.351 & NS \\
\hline
\end{tabular}

P-value $<0.05$ : Significant [S]. The information is displayed as number [\%].

\section{DISCUSSION}

Effective postoperative analgesia can prevent hormonal, metabolic and cardiovascular responses to the stress of surgery and postoperative pain ${ }^{[9]}$.

Although, the gold standard for pain relief is an opioid, it increases postoperative nausea and vomiting and slow the gastrointestinal motility's recovery ${ }^{[10]}$.

Local anesthetics wound infiltration is an easy, effective and costless technique can enhance postoperative analgesia for different types of operations without major complications ${ }^{[6]}$.

This study was designed to assess the efficacy of ketamine and dexmedetomidine in local wound infiltration on pain relief in patients underwent cesarean section.
Regarding the time to the first request analgesia, it was longer in group A and group B than in group C. This reflects the efficacy of ketamine and dexmedetomidine to provide adequate and extensive analgesia in local wound infiltration, which may be attributed to the synergistic effect of these drugs on combination with bupivacaine, but ketamine provided the longest time with superior analgesia. A significant decrease in total pethidine consumption in group $A$ than group $B$ and group $C$ had been reported.

In agreement with our results, Mohamed et al. [8] reported prolonged time to the first analgesic request and less morphine consumption in ketamine and dexmedetomidine groups compared with the control group in major abdominal cancer surgery.

The results of our study were in accordance with the result of Kaler et al. ${ }^{[11]}$ who reported prolonged time for the 
first rescue analgesia in the ketamine group, with reduced total opioid consumption in lower segment cesarean section.

Also, Mitra et al. ${ }^{[12]}$ found a longer time to the first rescue analgesia in the dexmedetomidine group, and less diclofenac consumption in lumbar discectomy surgeries.

In line with our findings, Garg et al. [13] reported that pain-free periods were longer with the ketamine \& dexmedetomidine group than the control group with a significant decrease in the total analgesia required in spine surgery.

In agreement with our results, Ülgey et al. ${ }^{[14]}$ found that dexmedetomidine reduced time of rescue analgesic and total morphine consumption in total abdominal hysterectomy.

On the contrary, Medhat et al. ${ }^{[15]}$ reported no difference between the study groups regarding the time of the first analgesic request and opioid consumption in the subcostal transversus abdominis plane block in laparoscopic cholecystectomy. This may be attributed to the use of a small dose of ketamine [0.5 mg/kg] while we used [2 mg/kg] in our study.

Regarding visual analogue scale, it was significantly reduced in group $A \& B$ than group $C$, but ketamine was associated with superior analgesia.

In agreement with these findings, Mohamed et al. [8] reported a significant reduction in visual analogue scale in ketamine and dexmedetomidine groups than the control group in abdominal hysterectomy.

In addition, Tuchscherer et al. [16] demonstrated that ketamine [2mg/kg] subcutaneous infiltration provides adequate analgesia with lower visual analogue scale after cholecystectomy.

Also, Azemati et al. [17] concluded that an addition of dexmedetomidine to ropivacaine infiltration decreased post-inguinal herniorrhaphy pain without side effects.

Liu et al. [18] concluded that local anesthetic wound infiltration alone without adjuvants provides short-time analgesia postoperatively.

On the contrary, Medhat et al. [15] reported that insignificant difference was found between bupivacaine versus bupivacaine ketamine groups regarding visual analogue scale after laparoscopic cholecystectomy.
In the current study, early time of starting breastfeeding, time of passing flatus or stool and start of eating and time of starting movement were significantly higher among ketamine and dexmedetomidine groups than the control group.

Kaler et al. [11] reported that local anesthetic wound infiltration provides early ambulation, breast-feeding and passing flatus in the ketamine plus levobupivacaine group more than the levobupivacaine alone group.

Mohamed et al. [8] reported an insignificant difference among ketamine and dexmedetomidine groups regarding the time of starting movement.

Regarding side effects of medication, we observed 7 patients [27\%] with bradycardia in group $B$ versus one patient [4\%] in group $C$ while nil in group $A$. this could be attributed to the fact that dexmedetomidine has central inhibition of sympathetic outflow and decrease of nor adrenaline leading to bradycardia and hypotension [19].

No statistically significant difference was reported regarding nausea, vomiting, hypotension, dizziness, or hallucination.

Mohamed et al. [8] concluded that there were insignificant differences among the studied groups regarding side effects.

Garg et al. [13] demonstrated few patients in the ketamine group had nausea, dizziness, and diplopia, but statistically insignificant.

Conclusion: Ketamine in local wound infiltration was superior to dexmedetomidine as ketamine increased time to the first analgesia required and decreased total analgesic consumption.

\section{Conflict of interest}

All authors declare that there was no possible conflict of interest.

\section{REFERENCES}

1. Roofthooft E, Joshi GP, Rawal N, Van de Velde M; PROSPECT Working Group of the European Society of Regional Anesthesia and Pain Therapy and supported by the Obstetric Anesthetists' Association. PROSPECT guideline for elective caesarean section: updated systematic review and procedure-specific postoperative pain management recommendations. Anaesthesia. 2021 May; 76[5]:665-680. [DOI: 10.1111/ anae. 15339]. 
2. Carvalho B, Butwick AJ. Postcesarean delivery analgesia. Best Pract Res Clin Anaesthesiol. 2017 Mar;31[1]:69-79. [DOI: 10.1016/j.bpa.2017.01.003].

3. Wang SC, Pan PT, Chiu HY, Huang CJ. Neuraxial magnesium sulfate improves postoperative analgesia in Cesarean section delivery women: A meta-analysis of randomized controlled trials. Asian J Anesthesiol. 2017 Sep; 55 [3]: 5667. [DOI: 10.1016/j.aja.2017.06.005].

4. Peene L, Le Cacheux P, Sauter AR, Joshi GP, Beloeil H; PROSPECT Working Group Collaborators; European Society of Regional Anaesthesia. Pain management after laminectomy: a systematic review and procedure- specific post-operative pain management recommendations. Eur Spine J. 2020 Nov 27. [DOI: 10.1007/s00586-020-06661-8].

5. Abd El Hamed AS, Ahmed FK. Study of the effectiveness of local anesthetic wound infiltration on post- cesarean pain relief. AL-Azhar Assiut Med J. 2015; 13: 152-162.

6. Pettini E, Micaglio M, Bitossi U, De Gaudio AR, Degl'Innocenti $\mathrm{DR}$, Tofani L, et al. Influence of OPRM1 Polymorphism on Postoperative Pain After Intrathecal Morphine Administration in Italian Patients Undergoing Elective Cesarean Section. Clin J Pain. 2018; 34[2]:178-181. [DOI: 10.1097/AJP.0000000 000000 520].

7. Mansour Ghenaee M, Rahmani S, Jafarabadi M. Local lidocaine $2 \%$ in postoperative pain management in cesarean delivery. J Family Reprod Health. 2015 Mar; 9 [1]:19-21. [PMID: 25904963].

8. Mohamed SA, Sayed DM, El Sherif FA, Abd El-Rahman AM. Effect of local wound infiltration with ketamine versus dexmedetomidine on postoperative pain and stress after abdominal hysterectomy, a randomized trial. Eur J Pain. 2018 May; 22 [5]: 951-960. [DOI: 10.1002/ejp.1181].

9. Benka AU, Pandurov M, Galambos IF, Rakić G, Vrsajkov V, Drašković B. [Effects of caudal block in pediatric surgical patients: a randomized clinical trial]. Braz J Anesthesiol. 2020 Mar-Apr; 70[2]:97-103. [DOl: 10.1016/j.bjan.2019.12.003].

10. Nilsson U, Gruen R, Myles PS. Postoperative recovery: the importance of the team. Anaesthesia. 2020 Jan;75 Suppl 1:e158-e164. [DOI: 10.1111/anae.14869].

11. Kaler P, Verma I, Grewal A. Comparison of levobupivacaine alone versus levobupivacaine with ketamine in subcutaneous infiltration for postoperative analgesia in lower segment cesarean section. J Obstetric Anesthesia Crit Care 2019; 9: 60-4. [DOI: 10.4103/joacc.JOACC_25_19].
12. Mitra S, Purohit S, Sharma M. Postoperative Analgesia After Wound Infiltration With Tramadol and Dexmedetomidine as an Adjuvant to Ropivacaine for Lumbar Discectomies: A Randomized-controlled Clinical Trial. J Neurosurg Anesthesiol. 2017 Oct; 29 [4]: 433-438. [DOI: 10.1097/ANA. 0000000000000422].

13. Garg N, Panda NB, Gandhi KA, Bhagat H, Batra YK, Grover VK, Chhabra R. Comparison of Small Dose Ketamine and Dexmedetomidine Infusion for Postoperative Analgesia in Spine Surgery--A Prospective Randomized Double-blind Placebo Controlled Study. J Neurosurg Anesthesiol. 2016 Jan; 28 [1]:27-31. [DOI: 10.1097/ANA.0000000000000193].

14. Ülgey A, Güneş I, Bayram A. The Analgesic Effects of Incisional Levobupivacaine with Dexmedetomidine after Total Abdominal Hysterectomy. Erciyes Medical Journal/Erciyes Tip Dergisi. 2015; 37: 150-60.

15. Ahmed AM. Ultrasound Guided Subcostal Transversus Abdominis Plane Block for Intensive Care Postoperative Analgesia after Laparoscopic Cholecystectomy [Comparative Study Between Bupivacaine Versus Bupivacaine-Ketamine]. AIMJ 2020; 242-247. [DOI: 10.21608/aimj.2020.27457.1190].

16. Tuchscherer J, McKay WP, Twagirumugabe T. Low-dose subcutaneous ketamine for postoperative pain management in Rwanda: a dose-finding study. Can J Anaesth. 2017 Sep;64[9]:928-934. English. [DOl: 10.1007/s12630-0170914-0].

17. Azemati S, Pourali A, Aghazadeh S. Effects of adding dexmedetomidine to local infiltration of bupivacaine on postoperative pain in pediatric herniorrhaphy: a randomized clinical trial. Korean J Anesthesiol. 2020 Jun;73[3]:212-218. [DOI: 10.4097/kja.19111].

18. Liu X, Song T, Chen X, Zhang J, Shan C, Chang L, Xu H. Quadratus lumborum block versus transversus abdominis plane block for postoperative analgesia in patients undergoing abdominal surgeries: a systematic review and meta-analysis of randomized controlled trials. BMC Anesthesiol. 2020 Mar 2; 20 [1]: 53. [DOI: 10.1186/s12871020-00967-2].

19. Rekhi BK, Kaur T, Arora D, Dugg P. Comparison of Intravenous Dexmedetomidine with Midazolam in Prolonging Spinal Anaesthesia with Ropivacaine. J Clin Diagn Res. 2017 Feb; 11[2]:UC01-UC04. [DOI: 10.7860/JCDR/2017/23874. 9344]. 

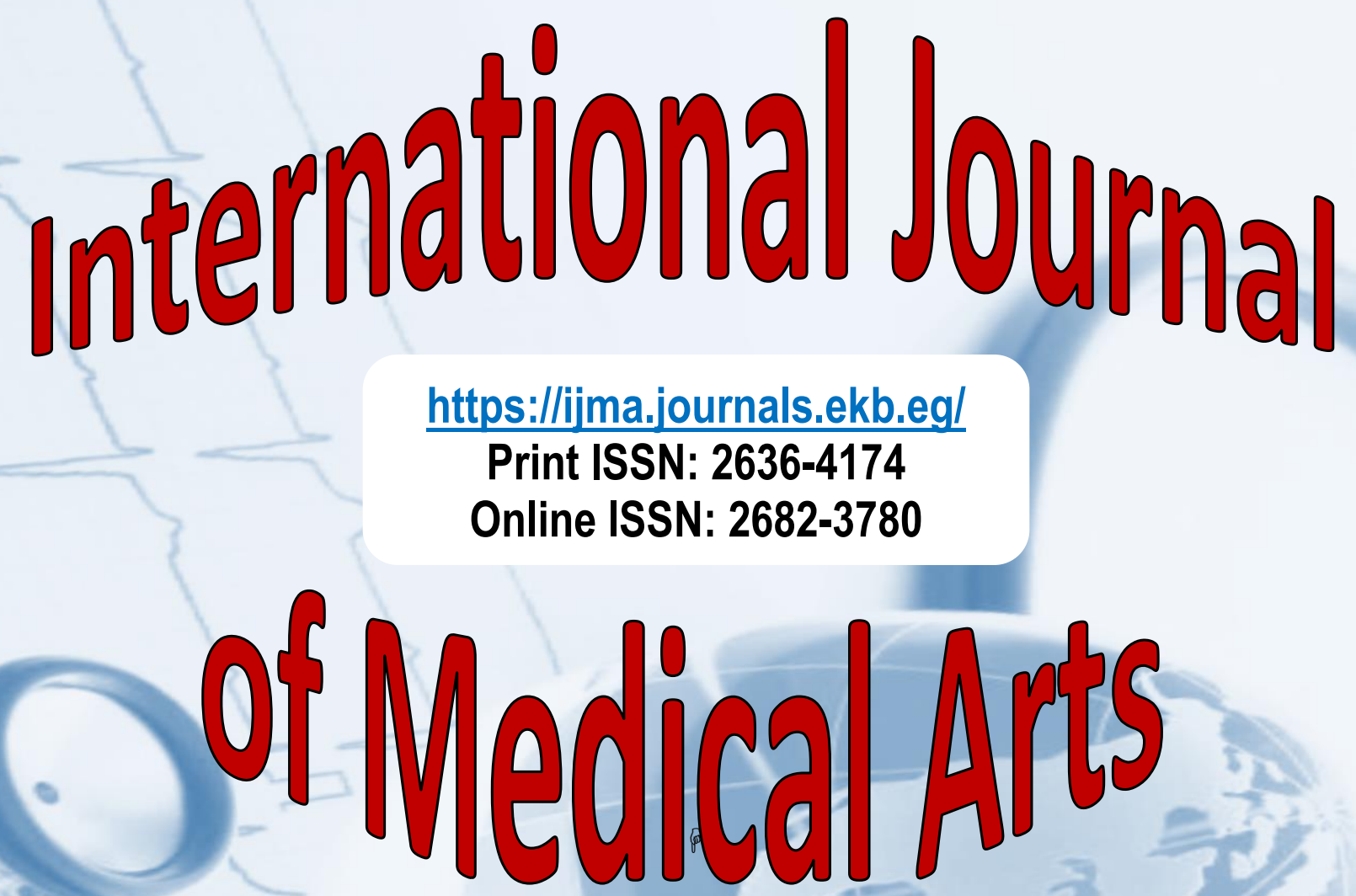